\title{
Methane-rich saline restores brain SOD activity and alleviates cognitive impairment in rats with traumatic brain injury
}

\author{
Fei-Di WANG ${ }^{1}$, Jie $\mathrm{LI}^{2}$, Xu ZHAI ${ }^{3}$, Rui $\mathrm{CHEN}^{3}$, Fang WANG ${ }^{2 *}$
}

\begin{abstract}
Clinically, methane is an anti-inflammatory gas used to treat organ damage. There is no extensive research on methane's repair of traumatic brain injury (TBI), so this study aims to investigate the role of methane and its potential mechanism. A rat TBI model was established by mechanical impact. SD rats were divided into four groups, including sham group, TBI group, 2 or $20 \mathrm{~mL} / \mathrm{kg}$ methane-rich saline (MS) group. Morris water maze test revealed that MS improved cognitive function in TBI rats. HE and Nissl staining showed that MS reduced the blurring of brain tissues boundary, the number of necrotic plaques and neurons in TBI rats. In addition, ELISA revealed that MS restored the oxidative stress of TBI rats and reversed the inflammatory effect of TBI on brain cells, and TUNEL staining detected that MS inhibited cell apoptosis. Western blotting showed that MS downregulated Caspase-3 and Bax protein levels and upregulated Bcl-2 level. And MS inhibited phosphorylated expressions of Janus kinase 1 (JAK1), signal transducer and activator of the transcription (STAT1) and NF- $k b-p 65$. In conclusion, MS improved cognitive function, reduced inflammatory response and oxidative stress and inhibited cell apoptosis to relieve rat TBI by blocking the activation of the JAK1/STAT1/NF-kb-p65 pathway.
\end{abstract}

Keywords: methane; traumatic brain injury; inflammation; cell apoptosis; the JAK1/STAT1/NF-кB-p65 pathway.

Practical Application: MS improves TBI rat oxidative stress and inflammation, reduces tissue damage and apoptosis.

\section{Introduction}

Traumatic brain injury (TBI) is one of the common severe diseases in neurosurgery, with high mortality and morbidity. It's also the most common cause of death and disability among young people. This syndrome may persist for a few days or last a lifetime, reducing the quality of life of patients with TBI. According to a research report, in the United States, TBI patients have an increased risk of death (Harrison-Felix et al., 2015), and about $30 \%$ of patients with TBI are permanently disabled (Faul et al., 2010). All of these clinical studies remind us that it's necessary to explore a powerful treatment for TBI based on its pathophysiological mechanism. The pathophysiological characteristics of TBI can be divided into primary injury and secondary injury. The secondary injury is related to neural inflammation, free radical accumulation, excitatory amino acid poisoning, mitochondrial dysfunction and calcium perturbation. TBI is considered as a complex and serious disease of the central nervous system, and negative effects in other systems can also be detected (Yin et al., 2016; Zygun et al., 2005). Respiratory organ dysfunction after TBI has been widely reported (Bratton \& Davis, 1997; Hendrickson et al., 2016). Acute respiratory distress syndrome (ARDS) would happen after TBI because it increased the susceptibility of the brain to subsequent hypoxia (Zink \& Feustel, 1995). Simultaneously, it's a consensus about the high possibility for TBI patients to have motor impairment (Tajiri et al., 2014; Yin et al., 2016). In addition, Liu et al.reported that TBI induced the intestinal mucosa damage and epithelial barrier dysfunction (Liu et al., 2017b). These studies indicated that TBI affected various systems with complex mechanism. Thus, it's obvious that symptomatic treatment is not feasible. TBI treatment urgently needs drugs that have positive effects on most systems.

Methane has been considered as an inert or biologically inactive gas since its discovery in 1778. Clinically, methane enters the body by injecting dissolved normal saline into the body and directly inhaling through the mouth. It has been widely reported that methane has positive effects on many systems, including digestive system (He et al., 2016; Jahng et al., 2012; Pimentel et al., 2006; Sahakian et al., 2010; Ye et al., 2015), respiratory system (Sun et al., 2017), immune system (Zhang et al., 2016), nervous system (Shen et al., 2016; Wang et al., 2017a, 2017b), motor system (Xin et al., 2016) and cardiovascular system (Chen et al., 2016). Methane has been revealed to have several biological properties, 
including anti-inflammation, anti-oxidant and anti-apoptosis. Methane activated pro-inflammatory cytokines via several pathways such as the PI3K-AKT-GSK-3 $\beta$ (Wang et al., 2017a) and the Nrf2-related (Ye et al., 2015). At the same time, it attenuated oxidant effect though increasing the levels of antioxidant factors (Ye et al., 2015) and decreasing the contents of oxidant factors such as malondialdehyde (MDA) and 3-nitrotyrosine (3-NT) (Fan et al., 2016). Additionally, Song et al.(Song et al., 2015) reported that B-cell lymphoma-2 (Bcl-2) level was increased after methane treatment of abdominal flap ischemia-reperfusion injury in rats, reflecting that methane had the ability of anti-apoptosis. Considering that TBI is a multi-system disorder and the biological properties of methane, we supposed that methane may have positive effects during TBI treatment. We first investigated the pathological changes after TBI though the percentage of brain tissue water content. To further explore the protective mechanism of methane-rich saline (MS) on TBI, the antioxidant and immune properties were measured. Finally, the anti-apoptotic effect of MS was illustrated by detecting the caspase- 3 protein level and the number of positive cells in TUNEL staining.

\section{Methods}

\subsection{Animals}

Forty-eight male Sprague-Dawley rats (weighing 200-220 g) were divided into four groups $(\mathrm{n}=12)$, and all the rats were initially housed in groups in a temperature-controlled $\left(23 \pm 2^{\circ} \mathrm{C}\right)$ environment under a 12/12 h light/dark cycle with free to obtain food and water for 2 weeks.

\subsection{Preparation of methane-rich saline}

Under high pressure (0.6 MPa), the purified methane stored in the gas canister was dissolved in normal saline for $3 \mathrm{~h}$ until it reached the supersaturation level. The saturated methane-rich saline was stored at $4{ }^{\circ} \mathrm{C}$ and atmospheric pressure, and was prepared $6 \mathrm{~h}$ before animal experiments to ensure stable injection concentration.

\subsection{Traumatic brain injury protocol}

Rats were anesthetized with pentobarbital sodium $(20 \mathrm{mg} / \mathrm{kg})$ placed onto a warm-bed and under a heating light. The head was fixed on a stereotactic frame with an ear bar. The skull was exposed, and a $2.5-\mathrm{mm}$ circular skull bone was removed by drilling in the center of the bregma and lambda $(-2 \mathrm{~mm}$ anteroposterior, $2.5 \mathrm{~mm}$ mediolateral to the bregma) to generate the window of impact. Impact was delivered by (depth of $2.5 \mathrm{~mm}$, velocity of $2 \mathrm{~m} / \mathrm{s}$ and duration time of $300 \mathrm{~ms}$ ) using an impacting apparatus (Stereotaxic Impactor, Leica). During the whole procedure, rats were placed onto a warm bed and heated under a heating lamp. The wound was covered with gauze soaked in salt water to prevent excessive fluid loss. The rats ( $\mathrm{n}=6$ per group) were killed at $24 \mathrm{~h}$ after successful modeling, and the brain tissues were collected for reserve.

\subsection{Experimental design}

Under pentobarbital sodium anesthesia, rats received TBI operations. Before the experiment, the rats fasted for $12 \mathrm{~h}$, but could drink water freely. The rats were divided into four groups: (1) sham operation group (rats underwent craniotomy, and then received intravenous drip of normal saline $(2 \mathrm{~mL} / \mathrm{kg})$ every $6 \mathrm{~h})$; (2) TBI group (rats underwent TBI operation, and then received intravenous drip of normal saline $(2 \mathrm{~mL} / \mathrm{kg})$ every $6 \mathrm{~h})$; (3) $\mathrm{TBI}+2 \mathrm{~mL} / \mathrm{kg}$ MS group (TBI was performed on rats, followed by intravenous infusion of MS ( $2 \mathrm{~mL} / \mathrm{kg})$ every $6 \mathrm{~h})$; and (4) TBI $+20 \mathrm{~mL} / \mathrm{kg}$ MS group (TBI was performed on rats, and then $20 \mathrm{~mL} / \mathrm{kg}$ MS was infused intravenously every 6 hours).

\subsection{Morris Water Maze (MWM)}

The MWM tests were performed as previously described (Zhuang et al., 2020). In short, 8-14 days after TBI or MS treatment, rats ( $\mathrm{n}=6$ per group) underwent MWM tests. The swimming speed and latency of rats were recorded every day. On the last day (day 14), we removed the platform and measured the platform crossing time of rats. After each experiment, we dried each rat in a container under a heating lamp for $5 \mathrm{~min}$, and then put them in their home cages.

\subsection{Brain histological examination}

After $24 \mathrm{~h}$ of treatment, the model was established successfully, and then rats were sacrificed by excess pentobarbital sodium. Then $200 \mu \mathrm{L}$ of PBS was perfused intracardially, followed by perfusion with $100 \mu \mathrm{L}$ of $4 \%$ paraformaldehyde (PFA) for $20 \mathrm{~min}$. The brain was removed and allowed to stand in 4\% PFA for $24 \mathrm{~h}$. After the paraffin section of brain tissue was made, it was dehydrated continuously dehydrated in different ethanol gradients $(80 \%$ for $1 \mathrm{~h}, 96 \%$ for $3 \mathrm{~h}$ and $100 \%$ for $3 \mathrm{~h}$ ), cleared for $2 \mathrm{~h}$ in pure xylophenol. And the paraffin at $56^{\circ} \mathrm{C}$ was allowed to stand for $2 \mathrm{~h}$, and then the sample was placed in a metal box to make a paraffin tissue block. Tissue sections of $4 \mu \mathrm{M}$ were performed, and finally H\&E and Nissl staining were performed. The basic dye used in Nissl staining was toluidine blue.

\subsection{Measurement of brain edema}

After the rats were executed, the brain tissues were quickly removed. Fresh anatomical tissue samples from the core of the hemispherical lesion were immediately weighed, and the weight of the wet tissues were recorded, and then they were dried in a constant temperature oven at $75^{\circ} \mathrm{C}$ for $24 \mathrm{~h}$ to keep the weight constant and record the weight (dry tissue). The percentage of brain tissue water content was calculated by the following Formula 1 to assess the degree of edema in brain tissue.

Water $\%=($ wet weight - dry weight $) /$ wet weight $\times 100 \%$

\subsection{Detection of antioxidant capacity}

The levels of MDA, 3-NT, 8-Hydroxy-desoxyguanosine (8-OhdG) and SOD were detected to detect lipid oxidation and antioxidant levels, respectively. Briefly, $1 \mathrm{~g}$ of brain tissues was melted, added $10 \mathrm{~mL}$ of normal saline, homogenized in a glass homogenizer, and centrifuged at 2,000 rpm. The supernatant after centrifugation was collected and the concentration of MDA was calculated by thiobarbituric 
acid method according to the manufacturer's instructions (Nanjing Jiancheng Bioengineering Institute, Nanjing, China). The contents of 3-NT, 8-OhdG and SOD in brain homogenate were evaluated by evaluating the 3-NT, 8-OhdG and SOD detection kits according to the manufacturer's instructions (Nanjing Jiancheng Bioengineering Institute, Nanjing, China).

\subsection{Enzyme-Linked Immuno Sorbent Assay (ELISA)}

After thawing, the brain tissues were weighed and dissolved in normal saline at $4{ }^{\circ} \mathrm{C}$, and then centrifuged at $2000 \mathrm{r} / \mathrm{min}$ for $15 \mathrm{~min}$. The levels of TNF- $\alpha$, IL- $1 \beta$ and IL- 6 in the supernatant were measured by using ELISA kits (R\&D Systems, Minneapolis, MN, USA), and the absorbance values were measured at $450 \mathrm{nM}$ (ELx800, BioTek, Vermont, USA).

\subsection{TUNEL staining}

Terminal deoxynucleotidyl transferase-mediated deoxyuridine triphosphate nick end labeling (TUNEL) was used to evaluate cell apoptosis. Apoptosis assay kit (KeyGen Biotech, Nanjing, China) was used to detect apoptosis and the number of apoptotic cells was calculated by using Image-Pro Plus 6.0 (Media Cybernetics, Silver, Spring, USA). We selected the 10 best fields of view and calculated the apoptotic index.

\subsection{Western blotting}

Hippocampal tissues were collected from each group at $24 \mathrm{~h}$ after the establishment of the model. Firstly, the tissues were weighed, then PBS buffer and protease inhibitor were added. Tissues were homogenated in tissue lysate (Beyotime Chemical Co, China). The supernatant was collected after centrifugation $15,000 \times \mathrm{g}$ for $10 \mathrm{~min}$ at $4{ }^{\circ} \mathrm{C}$. Then, the protein was quantitatively analyzed by using BCA protein analysis kits (Thermo Fisher scientiifc, Inc.). Loading buffer (Beijing Solarbio Science \& Technology Co., Ltd.) was added, boiled, denatured and stored at $-80^{\circ} \mathrm{C}$. The same quality protein was separated by sodium dodecyl sulfate polyacrylamide gel electrophoresis, transferred to the polyvinylidene fluoride membrane (EMD milipore) and sealed with 5\% nonfat milk in the Tris+Tween (TBST) buffer saline for
$1 \mathrm{~h}$ and incubated with rabbit monoclonal to caspase-3 (1:400, ab32351, Abcam, Cambridge, UK), rabbit monoclonal to Bax (1:400, ab32503, Abcam), rabbit monoclonal to Bcl-2 (1:300, ab182858, Abcam), rabbit monoclonal to JAK1 (1:400, ab133666, Abcam), rabbit monoclonal to STAT1 (1:500, ab109320, Abcam) and rabbit monoclonal to NF-kB p65 (1:400, ab32536, Abcam) overnight at $4{ }^{\circ} \mathrm{C}$. Then, the membranes were incubated with horseradish peroxidase (HRP)-conjugated goat anti-rabbit IgG (1:1000, ab205718, Abcam) for $1 \mathrm{~h}$. The protein bands were visualized with ECL detection reagents and analyzed with Image J software (National Insitutes of Health, Bethesda, MD, USA). GAPDH and $\beta$-actin were used as the endogenous controls.

\subsection{Statistical analysis}

SPSS 21.0 software (SPSS, Chicago, USA) was used to analyze the data, and the results were expressed as mean \pm SEM. Student's t-test or One-way analysis of variance (ANOVA) was used to assess the differential expression. $P<0.05$ was considered to indicate a statistically signifcant difference.

\section{Results}

\subsection{MS treatment improved TBI induced cognitive impairment in rats}

MWM tests were used to test the spatial learning and memory ability of rats on days 8-14 after TBI or MS treatment. The swimming speed of rats in the TBI group was slower than sham group $(P<0.05)$, and $20 \mathrm{mg} / \mathrm{kg}$ MS treatment accelerated the swimming speed $(P<0.05)$ (Figure 1a). Moreover, the escape latency of rats in the TBI group was longer than that of rats in sham group $(P<0.05)$, and $2 \mathrm{mg} / \mathrm{kg}$ or $20 \mathrm{mg} / \mathrm{kg}$ MS treatment shortened the escape latency $(P<0.05)$ (Figure $1 \mathrm{~b})$. In addition, TBI treatment reduced the target platform crossing times of rats $(P<0.05)$, and $2 \mathrm{mg} / \mathrm{kg}$ or $20 \mathrm{mg} / \mathrm{kg}$ MS increased the target platform crossing times of rats $(P<0.05)$ (Figure 1c). And the improvement of cognitive function of TBI rats treated with $20 \mathrm{mg} / \mathrm{kg}$ MS was better than that of $2 \mathrm{mg} / \mathrm{kg}$ MS $(P<0.05)$. These results showed that MS treatment could improve TBI induced cognitive impairment in rats.
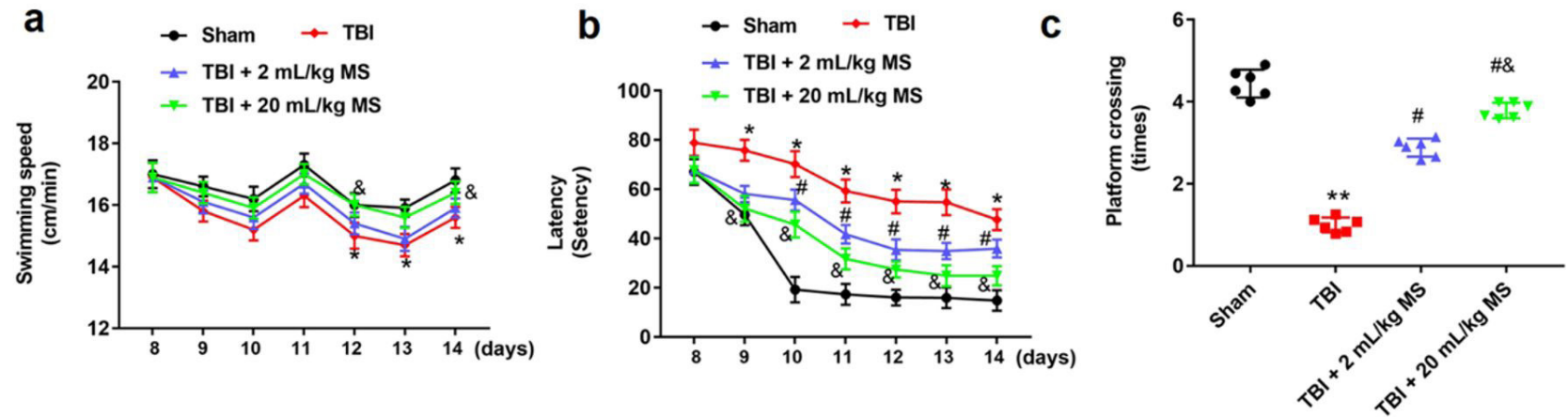

Figure 1. MS treatment improved TBI-induced cognitive impairment in TBI rats. (a) Swimming speed; (b) Latency; (c) Platform crossing, were detected in rats with different treatments including sham treatment, TBI treatment, TBI together with $2 \mathrm{~mL} / \mathrm{kg}$ MS treatment and TBI together with $20 \mathrm{~mL} / \mathrm{kg}$ MS treatment ( $\mathrm{n}=6$ per group). ${ }^{\star} P<0.05$, compared with sham group; ${ }^{\sharp} P<0.05$, compared with TBI group; ${ }^{\circledR} P<0.05$, compared with TBI $+2 \mathrm{~mL} / \mathrm{kg}$ MS group. 


\subsection{MS treatment alleviated brain tissue damage in TBI rats}

To explore the effect of methane, we compared the pathological sections of brain tissues of sham-operated, TBI rats, and MStreated TBI rats. As shown in Figure 2a, brain tissues in the sham surgery group had integrated infrastructures and clear boundary between gray and white matters, and blood vessels also exhibited normal morphology. Obviously, no apoptosis was found in the sham operation group, but the boundary of brain tissue in TBI group became blurred, and extensive hemorrhage occurred in both gray matter and white matter. Necrotic plaques were seen in the gray matter. In addition, gaps between cells and blood vessels became relatively larger. A portion of neurons were found with condensed nuclei and darkly red stained cytoplasm, and some apoptotic bodies were found. In MS treated TBI rats, the degree of neuron damage was between sham operation and TBI treatment, and MS treatment was dose-dependent. The brain tissue lacked clear basic structure and cell boundary in MS treatment group, but the degree of hemorrhage, necrosis and surrounding tissue edema was lower than that of TBI treated rats.

Nissl staining showed that neurons in the brains of sham-operated rats were intact and granular (Figure 2b), and the intracellular toluidine blue staining was obvious, indicating that the nutritional supply and energy synthesis of neurons were normal. In TBI group, the number of neurons was significantly reduced and the morphology was irregular, and toluidine blue staining in the cells was also significantly reduced, showing a fuzzy distribution in a small range. TBI induced neuronal necrosis and apoptosis, which led to neuronal loss. Remaining neurons had difficulty in energy synthesis, which resulted in neuronal dysfunction. In MS group, the number of neurons was reduced, and the effect of $20 \mathrm{~mL} / \mathrm{kg}$ MS was better than that of $2 \mathrm{~mL} / \mathrm{kg}$ MS.

\subsection{MS improved brain edema in TBI rats}

The brain edema was detected in rats with different treatments. As shown in Figure 3a, the brain water contents were increased in TBI group, and $2 \mathrm{mg} / \mathrm{kg}$ or $20 \mathrm{mg} / \mathrm{kg}$ MS treatment decreased the brain water contents $(P<0.05)$. However, there was no obvious different between $2 \mathrm{mg} / \mathrm{kg}$ and $20 \mathrm{mg} / \mathrm{kg}$ on the protective effect of edema in TBI model rats $(P>0.05)$. These results suggested that MS treatment could rescue brain edema, but the dose-dependent effect was not obvious.

\subsection{MS treatment alleviated the oxidative stress in TBI rats}

In order to investigate the protective effect of MS on TBI, the contents of MDA, 3-NT, 8-OhdG and SOD in brain tissues were measured in rats with different treatments. We found that TBI treatment increased the contents of MDA, 3-NT and 8 -OhdG, and $2 \mathrm{~mL} / \mathrm{kg}$ and $20 \mathrm{~mL} / \mathrm{kg}$ MS treatments decreased the contents of MDA, 3-NT and 8-OhdG (Figure 3b-d). However, the SOD content in brain tissues was decreased in TBI group, and it was increased in $2 \mathrm{~mL} / \mathrm{kg}$ and $20 \mathrm{~mL} / \mathrm{kg} \mathrm{MS}$ groups (Figure 3e). Our results showed that the effects of MS on SOD, 3-NT and MDA were dose-dependent, that is, the therapeutic effect of $20 \mathrm{~mL} / \mathrm{kg}$ MS was better than $2 \mathrm{~mL} / \mathrm{kg}$ MS. These results indicated that MS alleviated the oxidative stress in TBI rat brain.

\subsection{MS treatment alleviated the pro-inflammatory effect of TBI in TBI rats}

To further explore the possibility of the protective effect of methane on TBI injury, we measured the levels of inflammatory factors in hippocampus homogenate of rats treated with different treatment methods. The contents of TNF- $\alpha$, IL- $1 \beta$ and IL-6 in brain homogenate of rats were all increased in TBI rats, and TNF- $\alpha$, IL- $1 \beta$ and IL- 6 contents were decreased in 2 and $20 \mathrm{~mL} / \mathrm{kg}$ MS treatment groups (Figure $3 \mathrm{f}-\mathrm{h}$ ). Moreover, we found that the effect of $20 \mathrm{~mL} / \mathrm{kg}$ MS was better than $2 \mathrm{~mL} / \mathrm{kg}$ in relieving inflammation. These results indicated that MS had anti-inflammatory effect. a

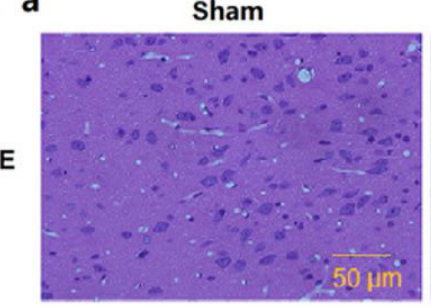

b

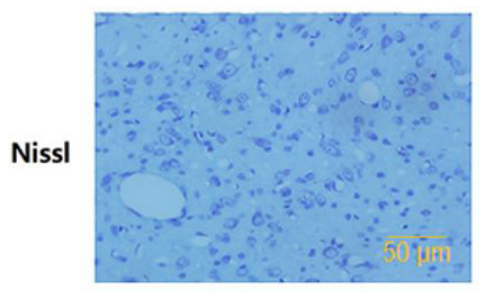

TBI

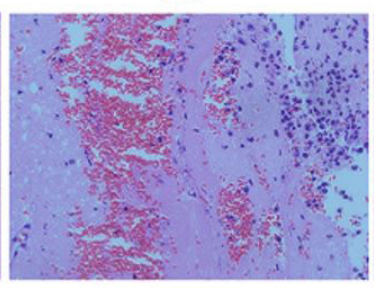

TBI
$\mathrm{TBI}+2 \mathrm{~mL} / \mathrm{kg} \mathrm{MS}$

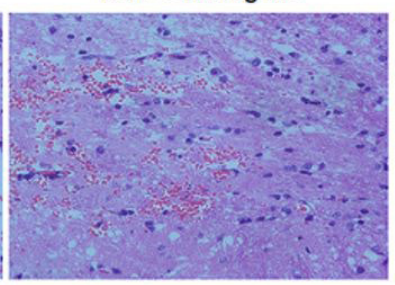

$\mathrm{TBI}+2 \mathrm{~mL} / \mathrm{kg} \mathrm{MS}$

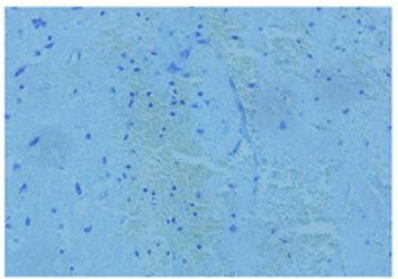

$\mathrm{TBI}+20 \mathrm{~mL} / \mathrm{kg} \mathrm{MS}$

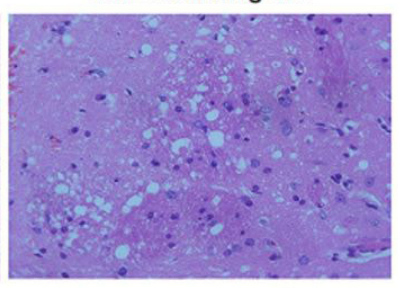

$\mathrm{TBI}+20 \mathrm{~mL} / \mathrm{kg} \mathrm{MS}$

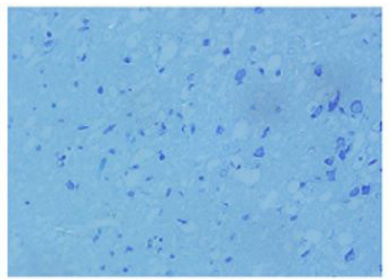

Figure 2. Morphological observation of brain tissues in rats. $(a, b)$ The brain tissues were stained with H\&E and Nissl staining after rats were treated by sham operation, TBI, or two doses $(2$ or $20 \mathrm{~mL} / \mathrm{kg}$ ) of MS treatments (original magnification $\times 200$ ). 

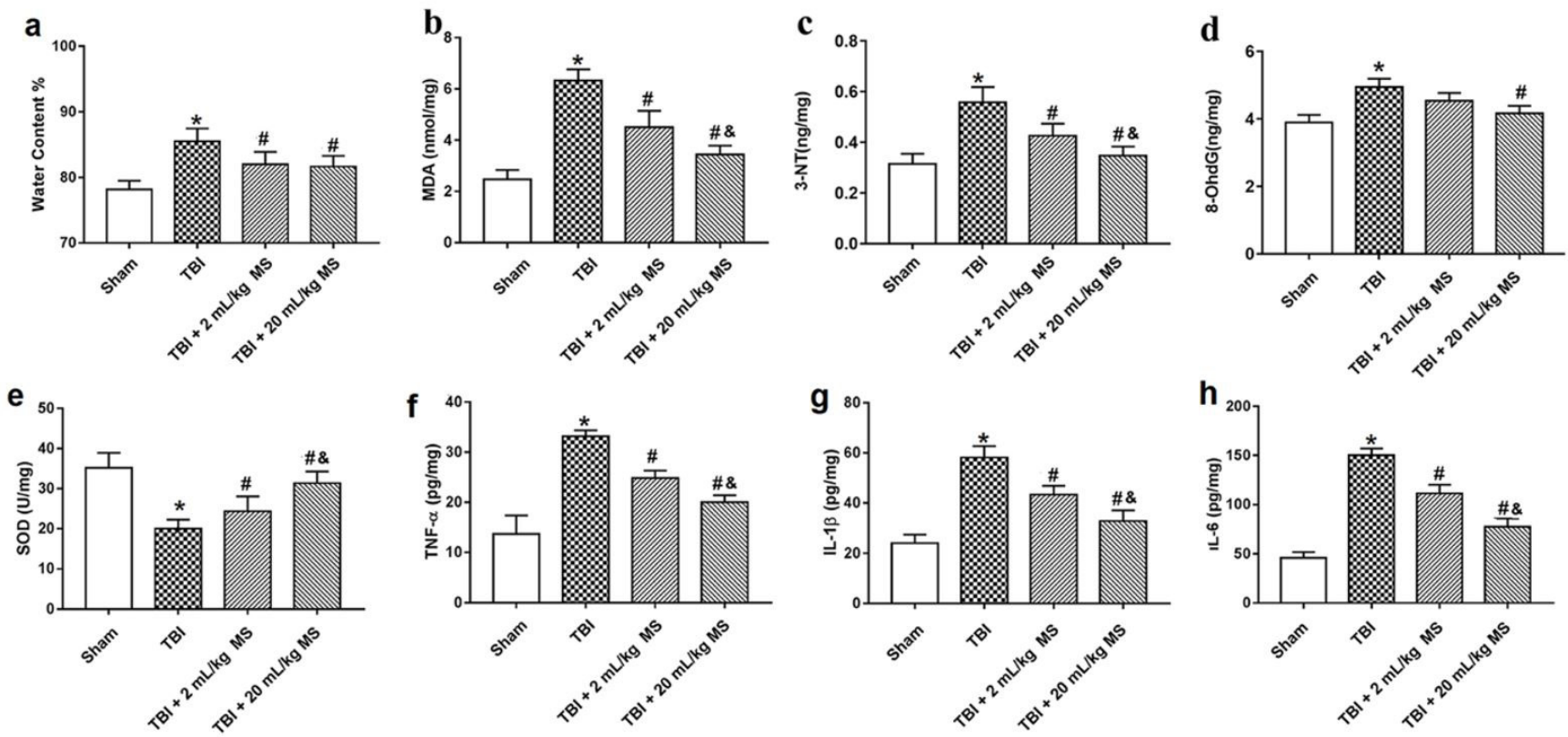

Figure 3. MS treatment alleviated brain edema, oxidative stress injury and inflammation in TBI rats. Rats were treated by sham treatment, TBI treatment, TBI together with $2 \mathrm{~mL} / \mathrm{kg}$ MS treatment and TBI together with $20 \mathrm{~mL} / \mathrm{kg}$ MS treatment. (a) The water contents were detected in rat brain tissues; (b-e) The contents of MDA, 3-NT, 8-OhdG and SOD activity were detected by ELISA kits; (f-h) The contents of TNF- $\alpha$, IL-1 $\beta$ and IL- 6 were detected with ELISA kits. ${ }^{\star} P<0.05$, compared with sham group; ${ }^{*} P<0.05$ compared with TBI group, ${ }^{\circledR} P<0.05$ compared with TBI $+2 \mathrm{~mL} / \mathrm{kg}$ MS group.

\subsection{MS treatment reversed the pro-apoptotic effect of TBI rat brain cells}

TUNEL method was used to detect apoptosis of rat brain cells. The results showed that TBI enhanced brain cell apoptosis, and $2 \mathrm{~mL} / \mathrm{kg}$ and $20 \mathrm{~mL} / \mathrm{kg}$ treatments inhibited cell apoptosis $(P<0.05)$. Moreover, we found that $20 \mathrm{~mL} / \mathrm{kg} \mathrm{MS}$ was better than $2 \mathrm{~mL} / \mathrm{kg}$ MS in inhibiting cell apoptosis (Figure $4 \mathrm{a}, \mathrm{b}$ ). In addition, Western blot assay was used to detect caspase- 3 protein level in brain tissues (Figure 5a,b). The result showed that TBI significantly increased caspase- 3 protein level in brain tissues of rats $(P<0.05)$, while MS reversed the promoting effect of TBI on caspase- 3 protein in brain tissues of rats, and the therapeutic effect of $20 \mathrm{~mL} / \mathrm{kg} \mathrm{MS}$ was better than $2 \mathrm{~mL} / \mathrm{kg}$ (Figure $5 \mathrm{~b}$ ). Consistent with the western blot result of caspase-3, TBI increased the Bax protein level in brain tissues of rats, and MS decreased the Bax protein level $(P<0.05)$. However, Bcl-2 protein level was downregulated in TBI group, and $2 \mathrm{~mL} / \mathrm{kg}$ and $20 \mathrm{~mL} / \mathrm{kg}$ treatments increased the Bcl-2 protein level $(P<0.05)$ (Figure 5c, d). These results confirmed that TBI could promote the apoptosis of brain cells, and MS treatment could protect the apoptosis of brain cells.

\subsection{MS treatment blocked the activation of the JAK1/STAT1/ NF- $\kappa B$ pathway induced by TBI}

The JAK1/STAT1/NF- $\kappa$ B pathway is responsible for inflammatory cytokine production in mammals. In this research, we investigated whether the JAK1/STAT1/NF- $\kappa$ B-p65 pathway also plays an important role in the treatment of TBI rats. Our results indicated that TBI treatment promoted the levels of phosphorylated JAK1,
STAT1 and NF- $\kappa$ B p65 proteins, while MS treatment reversed the activation of the JAK1/STAT1/NF- $\kappa$ B-p65 signal pathway induced by TBI and inhibited the phosphorylation of JAK1, STAT1 and NF- $\mathrm{BB}-\mathrm{p} 65$ proteins (Figure 5e, f). These results suggested that MS could alleviate TBI by blocking the JAK1/ STAT1/NF- $\kappa$ B-p65 signaling pathway.

\section{Discussion}

Methane rescues the noxious stimulation of traumatic brain injury through suppressing inflammatory response, oxidative stress and apoptosis in rats. Here, we demonstrated that after TBI, methane treatment showed great ability to rescue it though the antiinflammation, anti-oxidant and anti-apoptotic properties. These results indicated the potential of methane in the clinical treatment of TBI.

Abnormal structures reflect structure related dysfunction. Yin et al.reported that acute axonal degeneration drove development of cognitive, motor, and visual deficits (Yin et al., 2016). As one of complex and serious diseases of central nervous system, it's indispensable to test the pathological changes of brain after TBI modeling. Here, we first used H\&E staining and Nissl staining to measure the morphological changes and loss of neural cells. The results of histopathological staining confirmed the protective effects of MS on brain.

During the initial $24 \sim 72 \mathrm{~h}$ following TBI, a series of vascular, cellular, and molecular processes follow, such as blood-brain barrier (BBB) disruption, edema formation, apoptosis, inflammation, and excitotoxicity, which result in additional, that is secondary, tissue damage with a progression from the core to adjacent primarily 
a
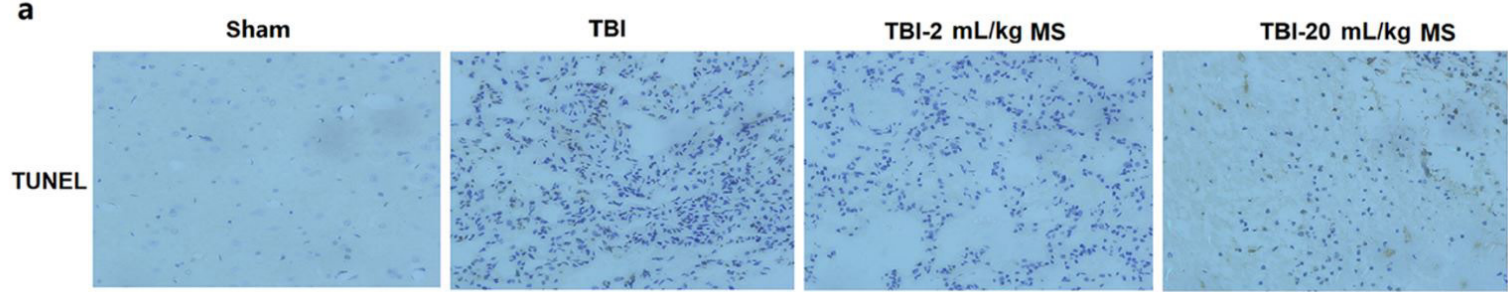

b

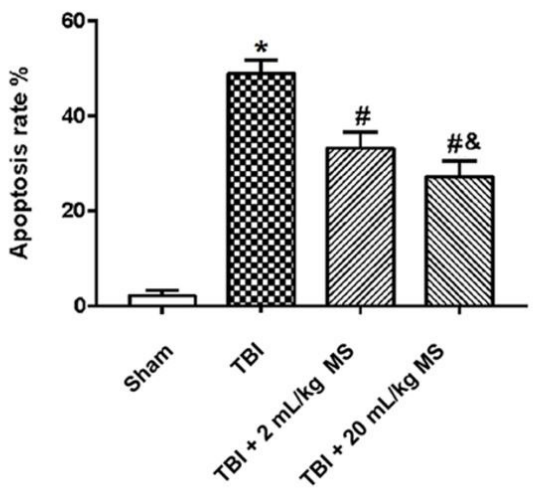

Figure 4. MS reduced neural cell apoptosis induced by TBI. (a) The brain tissues were stained with TUNEL after rats were treated by sham treatment, TBI treatment, TBI together with $2 \mathrm{~mL} / \mathrm{kg}$ MS treatment and TBI together with $20 \mathrm{~mL} / \mathrm{kg}$ MS treatment (original magnification $\times 200$ ); (b) Cell apoptosis rate were measured by calculating TUNEL-positive cell count of neural cells. ${ }^{\star} P<0.05$, compared with sham group; ${ }^{\#} P<0.05$ compared with TBI group, ${ }^{\&} P<0.05$ compared with TBI $+2 \mathrm{~mL} / \mathrm{kg}$ MS group.
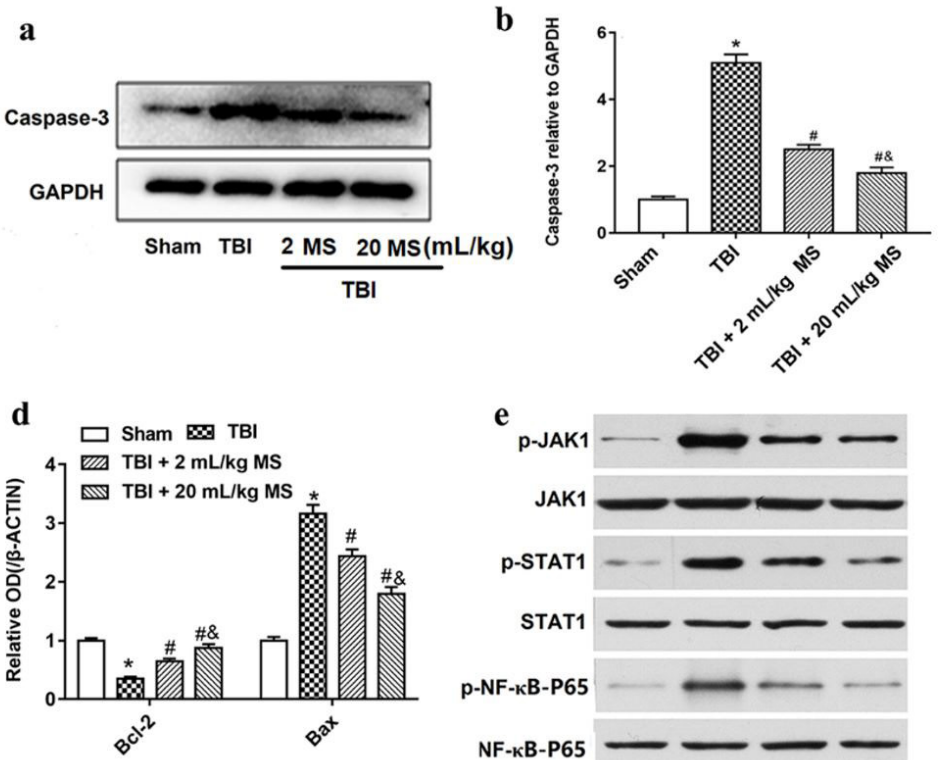

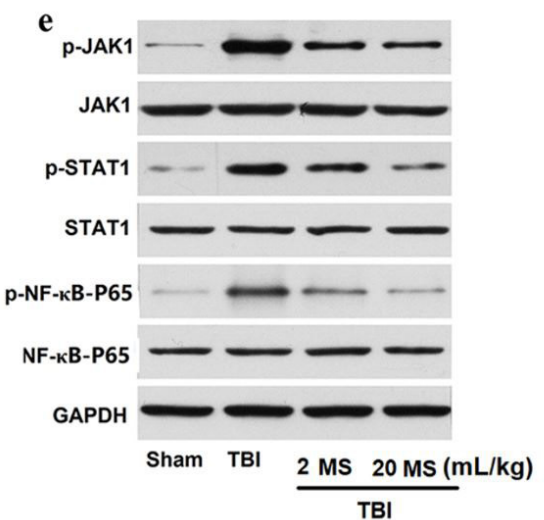

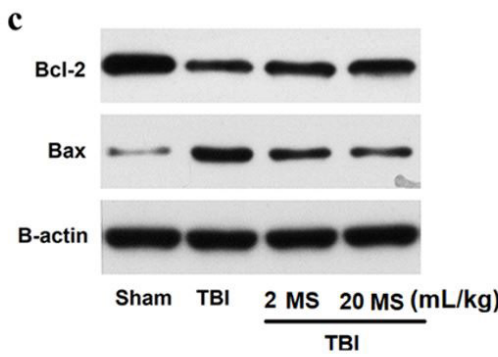

f
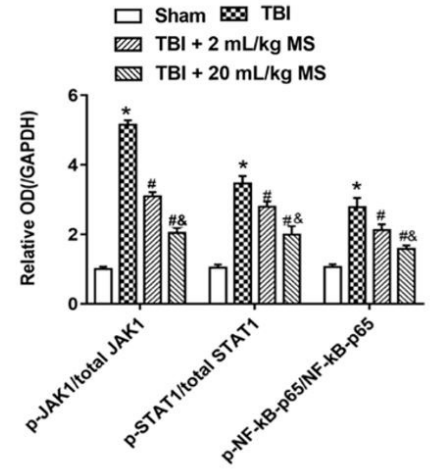

Figure 5. MS treatment reduced cell apoptosis and inhibited the activation of the JAK1-STAT1-NF- $\kappa B$ signaling pathway. Western blot assay was used to measure the protein levels of caspase-3 (a, b), Bcl-2, Bax (c, d), p-JAK1, p-STAT1 and NF- $\kappa B$ p-p65 (e, f) in rat brains. ${ }^{\star} P<0.05$, compared with sham group; ${ }^{*} P<0.05$ compared with TBI group, ${ }^{\circledR} P<0.05$ compared with TBI $+2 \mathrm{~mL} / \mathrm{kg}$ MS group.

uninjured tissue (Michinaga \& Koyama, 2015; Winkler et al., 2016). Considering that the development of cerebral edema with brain swelling was the most significant predictor of TBI outcome
(Donkin \& Vink, 2010), the brain water content was selected as a parameter to indicate the pathological changes and to evaluate the positive effects of methane during TBI treatment. Compared 
with sham group, rats in TBI groups significantly showed higher level of water content, which overlaps with previous TBI studies (Donkin \& Vink, 2010; Higashida et al., 2011; Zhao et al., 2005). After MS treatment, the water content of brain was decreased. This confirmed that methane can rescue the negative effect of TBI.

At present, the research on methane efficacy after TBI is not very extensive, it's essential to find out the probable mechanisms of its protective effect. Potts et al., 2006 and Wang et al., 2021a suggested to regard inflammation, oxidative injury, and ironmediated damage as potential therapeutic targets of brain injury. Based on previously reported biological characteristics of methane (Song et al., 2015; Wang et al., 2017b; Yao et al., 2017), we supposed that methane protects brain via anti-inflammation, anti-oxidant and anti-apoptotic mechanisms. MDA is a classic factor regarded as index of lipid peroxidation (Draper \& Hadley 1990), meanwhile, and SOD is considered as the first line of defense against oxygen free radicals (Wang et al., 2018). Ding et al.(Ding et al., 2014) reported that MDA content was increased and SOD content was decreased in brain tissues after TBI modeling. In the current study, we chose MDA, SOD, 3-NT, 8-OhdG and classic inflammation factors including the contents of TNF- $\alpha$, IL- 6 and IL- $1 \beta$ to detect the probable anti-oxidant and anti-inflammation mechanism of methane protective effects. Additionally, the level of caspase- 3 protein and the number of positive cells were detected by TUNEL staining to explore its anti-apoptotic effect. Our results showed the obvious mechanisms of methane protective effects after TBI, including anti-inflammation, anti-oxidant and anti-apoptotic. What's more, the significant results between $2 \mathrm{~mL} / \mathrm{kg}$ MS for the treatment of TBI group and $20 \mathrm{~mL} / \mathrm{kg}$ MS for the treatment of TBI group reflected the dose-dependent characteristic of methane protective effect.

In recent years, there are many studies on the treatment of brain injury by inhibiting the phosphorylation of NF- $\mathrm{kB}$ (Zhang et al., 2020). NF- $\mathrm{KB}$ mediates inflammatory and apoptotic responses. Blocking the NF-kB-mediated PI3K/Akt/mTOR signaling pathway could alleviate ischemia-reperfusion injury in rats (Wang et al., 2021b). Many studies have shown that inhibition of NF-kB-mediated inflammatory and apoptotic responses can protect mice from permanent cerebral ischemia injury (Liu et al., 2017a; Zhang et al., 2017), alleviate hypoxic-ischemic brain injury in neonatal rats (Tang et al., 2018) and protect traumatic brain injury in rats. STAT1 mediates the intracellular signaling pathway, which starts at the receptor on the surface of cytokine cells and transmits to the nucleus. It was found that the destruction of NF- $\kappa$ B or the activation of STAT- 1 could protect the brain from ischemia-reperfusion injury (Hou et al., 2010; Li et al., 2021). It has also been shown that the JAK/STAT signaling pathway can reduce the damage of blood-brain barrier during ischemia-reperfusion injury (Gong et al., 2019) and change the expression of pro-inflammatory and anti-inflammatory genes in the brain of rats (Damm et al., 2013). Our results showed that the JAK1/STAT1/NF-kB-p65 signaling pathway was activated by TBI treatment in rats, and the phosphorylated levels of JAK1, STAT1 and NF- $\mathrm{BB}-\mathrm{p} 65$ were significantly increased. In addition, we found that the JAK1/STAT1/NF-kB-p65 pathway was blocked after MS treatment, and the inhibition effect of $20 \mathrm{~mL} / \mathrm{kg}$ MS was stronger than that of $2 \mathrm{~mL} / \mathrm{kg} \mathrm{MS}$, indicating that methane can alleviate brain damage by inhibiting the JAK1/STAT1/NF-кB-P65 pathway. According to the report, methane improved the cognitive impairment of the aged mice by inhibiting the NF-kB/MAPKs pathway of microglia (Zhang et al., 2019a), whereas, there are not largely studies on methane alleviating brain injury by inhibiting the JAK1/STAT1/NF-кB-P65 pathway. Therefore, our results can provide a new field of vision for methane treatment of brain trauma.

Taken all results together, methane showed great potential for treating TBI via the protective mechanisms of anti-inflammation, anti-oxidant and anti-apoptotic. Although the results here cannot prove the dose dependent characteristic of methane protective effect, we propose a hypothesis. The reason for the hypothesis is that we have already observed a dose dependent effect during the investigation of methane protective effect. Further studies are required to investigate higher dose of methane and to conduct experiments on volunteers since it's the first step for methane to apply in clinical work.

In conclusion, our results demonstrated that methane can exert a protective role against TBI via the protective mechanisms including anti-oxidative, anti-inflammatory and anti-apoptotic. Due to the properties of non-toxic and high membrane permeability, methane may be a new therapeutic gas. In addition, methane-saturated saline is portable, easily administered and relatively stable, which could offer a new therapeutic strategy to clinical application in TBI.

\section{Abbreviations}

TBI: Traumatic brain injury. MS: methane-rich saline. MWM: morris water maze. ELISA: enzyme-linked immune sorbent assay. JAK1: Janus kinase 1. STAT1: signal transducer and activator of the transcription. ARDS: acute respiratory distress syndrome. MDA: malondialdehyde. 3-NT: 3-nitrotyrosine. Bcl-2: B-cell lymphoma-2. PFA: paraformaldehyde. 8-OhdG: 8-Hydroxy-desoxyguanosine. TUNEL: terminal deoxynucleotidyl transferase-mediated deoxyuridine triphosphate nick end labeling. HRP: horseradish peroxidase. ANOVA: one-way analysis of variance. BBB: blood-brain barrier.

\section{Ethical approval}

All animal experiments were approved by the Animal Experimentation Ethics Committee, Xian Jiaotong University. All animals were provided by the Laboratory Animal Services Center of Xian Jiaotong University. All methods were performed in accordance with the recommendations in the Guide for the Care and Use of Laboratory Animals of the National Institutes of Health (NIH).

\section{Conflict of interest}

All authors declare no conflicts of interest associated with this manuscript.

\section{Availability of data and material}

The datasets used during the present study are available from the corresponding author upon reasonable request.

\section{Funding}

This work was supported by the National Natural Science Foundation of China [No.:81701223]; the Natural Science Foundation in Shaanxi province [No.:2017JQ8019] and the Fundamental Research Funds for the Central Universities [No.: 1191329737]. 


\section{Author contributions}

Fei-Di Wang and Fang Wang designed the study. Jie Li, Xu Zhai and Rui Chen collected and analysed the data. Fei-Di Wang, $\mathrm{Jie} \mathrm{Li}$, and $\mathrm{Xu}$ Zhai contributed samples collection and intellectual input. Fei-Di Wang drafted and wrote the manuscript. Fang Wang revised the manuscript critically for intellectual content. All authors gave intellectual input to the study and approved the final version of the manuscript.

\section{References}

Bratton, S. L., \& Davis, R. L. (1997). Acute lung injury in isolated traumatic brain injury. Neurosurgery, 40(4), 707-712. http://dx.doi. org/10.1097/00006123-199704000-00009. PMid:9092843.

Chen, O., Ye, Z., Cao, Z., Manaenko, A., Ning, K., Zhai, X., Zhang, R., Zhang, T., Chen, X., Liu, W., \& Sun, X. (2016). Methane attenuates myocardial ischemia injury in rats through anti-oxidative, anti-apoptotic and anti-inflammatory actions. Free Radical Biology \& Medicine, 90, 1-11. http://dx.doi.org/10.1016/j.freeradbiomed.2015.11.017. PMid:26585905.

Damm, J., Harden, L. M., Gerstberger, R., Roth, J., \& Rummel, C. (2013). The putative JAK-STAT inhibitor AG490 exacerbates LPS-fever, reduces sickness behavior, and alters the expression of pro- and anti-inflammatory genes in the rat brain. Neuropharmacology, 71, 98-111. http://dx.doi.org/10.1016/j.neuropharm.2013.03.014. PMid:23548702.

Ding, K., Wang, H., Xu, J., Li, T., Zhang, L., Ding, Y., Zhu, L., He, J., \& Zhou, M. (2014). Melatonin stimulates antioxidant enzymes and reduces oxidative stress in experimental traumatic brain injury: the Nrf2-ARE signaling pathway as a potential mechanism. Free Radical Biology \& Medicine, 73, 1-11. http://dx.doi.org/10.1016/j. freeradbiomed.2014.04.031. PMid:24810171.

Donkin, J. J., \& Vink, R. (2010). Mechanisms of cerebral edema in traumatic brain injury: therapeutic developments. Current Opinion in Neurology, 23(3), 293-299. http://dx.doi.org/10.1097/ WCO.0b013e328337f451. PMid:20168229.

Draper, H. H., \& Hadley, M. (1990). Malondialdehyde determination as index of lipid-peroxidation. Methods in Enzymology, 186, 421-431. http://dx.doi.org/10.1016/0076-6879(90)86135-I. PMid:2233309.

Fan, D. F., Hu, H. J., Sun, Q., Lv, Y., Ye, Z. H., Sun, X. J., \& Pan, S. Y. (2016). Neuroprotective effects of exogenous methane in a rat model of acute carbon monoxide poisoning. Brain Research, 1633, 62-72. http://dx.doi.org/10.1016/j.brainres.2015.12.019. PMid:26711852.

Faul, M., Xu, L., Wald, M. M., Coronado, V., \& Dellinger, A. M. (2010). Traumatic brain injury in the united states: national estimates of prevalence and incidence, 2002-2006. Injury Prevention, 16(Suppl. 1), A268. http://dx.doi.org/10.1136/ip.2010.029215.951.

Gong, P., Zhang, Z., Zou, Y., Tian, Q., Han, S., Xu, Z., Liao, J., Gao, L., Chen, Q., \& Li, M. (2019). Tetramethylpyrazine attenuates bloodbrain barrier disruption in ischemia/reperfusion injury through the JAK/STAT signaling pathway. European Journal of Pharmacology, 854, 289-297. http://dx.doi.org/10.1016/j.ejphar.2019.04.028. PMid:31004602.

Harrison-Felix, C., Pretz, C., Hammond, F. M., Cuthbert, J. P., Bell, J., Corrigan, J., Miller, A. C., \& Haarbauer-Krupa, J. (2015). Life expectancy after inpatient rehabilitation for traumatic brain injury in the united states. Journal of Neurotrauma, 32(23), 1893-1901. http://dx.doi.org/10.1089/neu.2014.3353. PMid:25057965.

He, R., Wang, L., Zhu, J., Fei, M., Bao, S., Meng, Y., Wang, Y., Li, J., \& Deng, X. (2016). Methane-rich saline protects against concanavalin
A-induced autoimmune hepatitis in mice through anti-inflammatory and anti-oxidative pathways. Biochemical and Biophysical Research Communications, 470(1), 22-28. http://dx.doi.org/10.1016/j. bbrc.2015.12.080. PMid:26721437.

Hendrickson, C. M., Howard, B. M., Kornblith, L. Z., Conroy, A. S., Nelson, M. F., Zhuo, H., Liu, K. D., Manley, G. T., Matthay, M. A., Calfee, C. S., \& Cohen, M. J. (2016). The acute respiratory distress syndrome following isolated severe traumatic brain injury. The journal of trauma and acute care surgery, 80(6), 989-997. http:// dx.doi.org/10.1097/TA.0000000000000982. PMid:26881489.

Higashida, T., Kreipke, C. W., Rafols, J. A., Peng, C., Schafer, S., Schafer, P., Ding, J. Y., Dornbos, D. 3rd, Li, X., Guthikonda, M., Rossi, N. F., \& Ding, Y. (2011). The role of hypoxia-inducible factor-1alpha, aquaporin-4, and matrix metalloproteinase- 9 in blood-brain barrier disruption and brain edema after traumatic brain injury. Journal of Neurosurgery, 114(1), 92-101. http://dx.doi. org/10.3171/2010.6.JNS10207. PMid:20617879.

Hou, Y. C., Liou, K. T., Chern, C. M., Wang, Y. H., Liao, J. F., Chang, S., Chou, Y. H., \& Shen, Y. C. (2010). Preventive effect of silymarin in cerebral ischemia-reperfusion-induced brain injury in rats possibly through impairing NF-kappaB and STAT-1 activation. Phytomedicine, 17(12), 963-973. http://dx.doi.org/10.1016/j.phymed.2010.03.012. PMid:20833521.

Jahng, J., Jung, I. S., Choi, E. J., Conklin, J. L., \& Park, H. (2012). The effects of methane and hydrogen gases produced by enteric bacteria on ileal motility and colonic transit time. Neurogastroenterology \& Motility, 24, 185-190.

Li, T., Wang, X. Y., \& Dong, K. (2021). Extraction and purification of oridonin from Rabdosia rubescens and its protective effect on intracerebral hemorrhage-induced brain injury in rats. Food Science and Technology [Ahead of print]. http://dx.doi.org/10.1590/fst.24921.

Liu, X., Zhang, X., Wang, F., Liang, X., Zeng, Z., Zhao, J., Zheng, H., Jiang, X., \& Zhang, Y. (2017a). Improvement in cerebral ischemiareperfusion injury through the TLR4/NF-kappaB pathway after Kudiezi injection in rats. Life Sciences, 191, 132-140. http://dx.doi. org/10.1016/j.lfs.2017.10.035. PMid:29080695.

Liu, Y., Bao, Z., Xu, X., Chao, H., Lin, C., Li, Z., Liu, Y., Wang, X., You, Y., Liu, N., \& Ji, J. (2017b). Extracellular signal-regulated kinase/ nuclear factor-erythroid2-like2/heme oxygenase-1 pathwaymediated mitophagy alleviates traumatic brain injury-induced intestinal mucosa damage and epithelial barrier dysfunction. Journal of Neurotrauma, 34(13), 2119-2131. http://dx.doi.org/10.1089/ neu.2016.4764. PMid:28093052.

Michinaga, S., \& Koyama, Y. (2015). Pathogenesis of brain edema and investigation into anti-edema drugs. International Journal of Molecular Sciences, 16(5), 9949-9975. http://dx.doi.org/10.3390/ ijms16059949. PMid:25941935.

Pimentel, M., Lin, H. C., Enayati, P., Van Den Burg, B., Lee, H. R., Chen, J. H., Park, S., Kong, Y., \& Conklin, J. (2006). Methane, a gas produced by enteric bacteria, slows intestinal transit and augments sm-9975all intestinal contractile activity. American journal of physiology. Gastrointestinal and liver physiology, 290(6), G1089-G1095. PMid:16293652.

Potts, M. B., Koh, S. E., Whetstone, W. D., Walker, B. A., Yoneyama, T., Claus, C. P., Manvelyan, H. M., \& Noble-Haeusslein, L. J. (2006). Traumatic injury to the immature brain: inflammation, oxidative injury, and iron-mediated damage as potential therapeutic targets. NeuroRx, 3(2), 143-153. http://dx.doi.org/10.1016/j.nurx.2006.01.006. PMid:16554253. 
Sahakian, A. B., Jee, S. R., \& Pimentel, M. (2010). Methane and the gastrointestinal tract digest. Digestive diseases and sciences, 55(8), 21352143. http://dx.doi.org/10.1007/s10620-009-1012-0. PMid:19830557.

Shen, M., Fan, D., Zang, Y., Chen, Y., Zhu, K., Cai, Z., Liu, Y., Sun, X., Liu, J., \& Gong, J. (2016). Neuroprotective effects of methane-rich saline on experimental acute carbon monoxide toxicity. Journal of the Neurological Sciences, 369, 361-367. http://dx.doi.org/10.1016/j. jns.2016.08.055. PMid:27653924.

Song, K., Zhang, M., Hu, J., Liu, Y., Liu, Y., Wang, Y., \& Ma, X. (2015). Methane-rich saline attenuates ischemia/reperfusion injury of abdominal skin flaps in rats via regulating apoptosis level. BMC Surgery, 15(1), 92. http://dx.doi.org/10.1186/s12893-015-0075-4. PMid:26228913.

Sun, A., Wang, W., Ye, X., Wang, Y., Yang, X., Ye, Z., Sun, X., \& Zhang, C. (2017). Protective effects of methane-rich saline on rats with lipopolysaccharide-induced acute lung injury. Oxidative Medicine and Cellular Longevity, 2017, 7430193. http://dx.doi. org/10.1155/2017/7430193. PMid:28553434.

Tajiri, N., Acosta, S. A., Shahaduzzaman, M., Ishikawa, H., Shinozuka, K., Pabon, M., Hernandez-Ontiveros, D., Kim, D. W., Metcalf, C., Staples, M., Dailey, T., Vasconcellos, J., Franyuti, G., Gould, L., Patel, N., Cooper, D., Kaneko, Y., Borlongan, C. V., \& Bickford, P. C. (2014). Intravenous transplants of human adipose-derived stem cell protect the brain from traumatic brain injury-induced neurodegeneration and motor and cognitive impairments: cell graft biodistribution and soluble factors in young and aged rats. The Journal of Neuroscience, 34(1), 313-326. http://dx.doi.org/10.1523/ JNEUROSCI.2425-13.2014. PMid:24381292.

Tang, R., Lin, Y. M., Liu, H. X., \& Wang, E. S. (2018). Neuroprotective effect of docosahexaenoic acid in rat traumatic brain injury model via regulation of TLR4/NF-Kappa B signaling pathway. The International Journal of Biochemistry \& Cell Biology, 99, 64-71. http://dx.doi. org/10.1016/j.biocel.2018.03.017. PMid:29597004.

Wang, L., Yao, Y., He, R., Meng, Y., Li, N., Zhang, D., Xu, J., Chen, O., Cui, J., Bian, J., Zhang, Y., Chen, G., \& Deng, X. (2017a). Methane ameliorates spinal cord ischemia-reperfusion injury in rats: antioxidant, anti-inflammatory and anti-apoptotic activity mediated by Nrf2 activation. Free Radical Biology \& Medicine, 103, 69-86. http:// dx.doi.org/10.1016/j.freeradbiomed.2016.12.014. PMid:28007572.

Wang, W., Huang, X., Li, J., Sun, A., Yu, J., Xie, N., Xi, Y., \& Ye, X. (2017b). Methane suppresses microglial activation related to oxidative, inflammatory, and apoptotic injury during spinal cord injury in rats. Oxidative Medicine and Cellular Longevity, 2017, 2190897. http:// dx.doi.org/10.1155/2017/2190897. PMid:28740568.

Wang, Y., Branicky, R., Noe, A., \& Hekimi, S. (2018). Superoxide dismutases: dual roles in controlling ROS damage and regulating ROS signaling. The Journal of Cell Biology, 217(6), 1915-1928. http:// dx.doi.org/10.1083/jcb.201708007. PMid:29669742.

Wang, L. Y., Liu, G. F., Shao, Z. T., Zhang, Q. Q., Yin, L. L., Xu, E. B., Li, B., Cui, X. X., \& Teng, H. T. (2021a). MicroR-146 protects against rat ischemia-reperfusion injury by targeting NF- $\kappa \mathrm{B}$-mediated $\mathrm{PI} 3 \mathrm{~K} / \mathrm{AKT} / \mathrm{mTOR}$ signaling pathway. Food Science and Technology [Ahead of print].

Wang, Y. F., Du, Y. M., Li, J., \& Xu, K. (2021b). Hydroxysafflor yellow A from safflower (Carthamus tinctorius L.) prevents cerebral ischemia-reperfusion injury in rats. Food Science and Technology [Ahead of print].

Winkler, E. A., Minter, D., Yue, J. K., \& Manley, G. T. (2016). Cerebral edema in traumatic brain injury: pathophysiology and prospective therapeutic targets. Neurosurgery Clinics of North America, 27(4), 473-488. http://dx.doi.org/10.1016/j.nec.2016.05.008. PMid:27637397.
Xin, L., Sun, X. J., \& Lou, S. J. (2016). Effects of methane-rich saline on the capability of one-time exhaustive exercise in male SD rats. PLoS One, 11(3), e0150925. http://dx.doi.org/10.1371/journal. pone.0150925. PMid:26942576.

Yao, Y., Wang, L., Jin, P., Li, N., Meng, Y., Wang, C., Xu, M., Zhang, Y., Bian, J., \& Deng, X. (2017). Methane alleviates carbon tetrachloride induced liver injury in mice: anti-inflammatory action demonstrated by increased PI3K/Akt/GSK-3 beta-mediated IL-10 expression. Journal of Molecular Histology, 48(4), 301-310. http://dx.doi.org/10.1007/ s10735-017-9728-1. PMid:28597201.

Ye, Z., Chen, O., Zhang, R., Nakao, A., Fan, D., Zhang, T., Gu, Z., Tao, H., \& Sun, X. (2015). Methane attenuates hepatic ischemia/ reperfusion injury in rats through antiapoptotic, anti-Inflammatory, and antioxidative actions. Shock, 44(2), 181-187. http://dx.doi. org/10.1097/SHK.0000000000000385. PMid:26009821.

Yin, T. C., Voorhees, J. R., Genova, R. M., Davis, K. C., Madison, A. M., Britt, J. K., Cintrón-Pérez, C. J., McDaniel, L., Harper, M. M., \& Pieper, A. A. (2016). Acute axonal degeneration drives development of cognitive, motor, and visual deficits after blast-mediated traumatic brain injury in mice. Eneuro, 3(5), ENEURO.0220-16.2016.

Zhang, D., Li, N., Wang, Y., Lu, W., Zhang, Y., Chen, Y., Deng, X., \& Yu, X. (2019a). Methane ameliorates post-operative cognitive dysfunction by inhibiting microglia NF-kappaB/MAPKs pathway and promoting IL-10 expression in aged mice. International Immunopharmacology, 71, 52-60. http://dx.doi.org/10.1016/j. intimp.2019.03.003. PMid:30877874.

Zhang, H., Sun, X., Xie, Y., Zan, J., \& Tan, W. (2017). Isosteviol sodium protects against permanent cerebral ischemia injury in mice via inhibition of NF-kappaB-mediated inflammatory and apoptotic responses. Journal of Stroke and Cerebrovascular Diseases, 26(11), 26032614. http://dx.doi.org/10.1016/j.jstrokecerebrovasdis.2017.06.023. PMid:28784277.

Zhang, X., Li, N., Shao, H., Meng, Y., Wang, L., Wu, Q., Yao, Y., Li, J., Bian, J., Zhang, Y., \& Deng, X. (2016). Methane limit LPS-induced NF-kappaB/MAPKs signal in macrophages and suppress immune response in mice by enhancing PI3K/AKT/GSK-3beta-mediated IL-10 expression. Scientific Reports, 6(1), 29359. http://dx.doi. org/10.1038/srep29359. PMid:27405597.

Zhang, Z., Song, Y., Li, F., Xu, Z., \& Huang, Q. (2020). Inhibiting nuclear factor-kappaB at different stages after intracerebral hemorrhage can influence the hemorrhage-induced brain injury in experimental models in vivo. Brain Research Bulletin, 155, 159-165. http://dx.doi. org/10.1016/j.brainresbull.2019.12.010. PMid:31857135.

Zhao, J., Moore, A. N., Clifton, G. L., \& Dash, P. K. (2005). Sulforaphane enhances aquaporin-4 expression and decreases cerebral edema following traumatic brain injury. Journal of Neuroscience Research, 82(4), 499-506. http://dx.doi.org/10.1002/jnr.20649. PMid:16211562.

Zhuang, X., Yu, Y., Jiang, Y., Zhao, S., Wang, Y., Su, L., Xie, K., Yu, Y., Lu, Y., \& Lv, G. (2020). Molecular hydrogen attenuates sepsis-induced neuroinflammation through regulation of microglia polarization through an mTOR-autophagy-dependent pathway. International Immunopharmacology, 81, 106287. http://dx.doi.org/10.1016/j. intimp.2020.106287. PMid:32058932.

Zink, B. J., \& Feustel, P. J. (1995). Effects of ethanol on respiratoryfunction in traumatic brain injury. Journal of Neurosurgery, 82(5), 822-828. http://dx.doi.org/10.3171/jns.1995.82.5.0822. PMid:7714608.

Zygun, D. A., Kortbeek, J. B., Fick, G. H., Laupland, K. B., \& Doig, C. J. (2005). Non-neurologic organ dysfunction in severe traumatic brain injury. Critical Care Medicine, 33(3), 654-660. http://dx.doi. org/10.1097/01.CCM.0000155911.01844.54. PMid:15753760. 